\title{
Evaluation of antimicrobial and anticancer activity of Rosemary Rosmarinus oficinalis leaves extracts on pathogenic bacteria and cancer cell lines

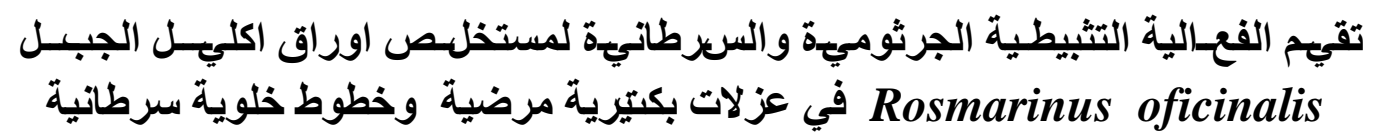

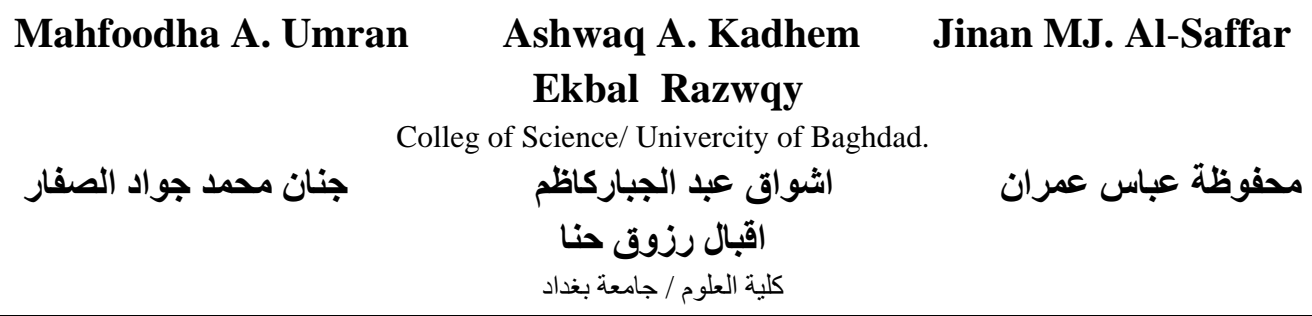

\section{Abstract}

The present study was carried out to detect the active constitutions extracted from Rosmarinus oficinalis leaves by 70\% methanol, the dried weight of aqueous extract (F1) were $12 \%(w: w)$ contain polyphenols represented by phenols, flavonoids and coumarins as a major compounds, while the dried weight of organic extract, [chloroform(F2)] was $2.8 \%(w: w)$ represented as terpenoids, tannins and coumarins detected by qualitative chemical analysis. Antimicrobial activity of Polyphenols and terpenoids were tested against four pathogenic bacteria isolates including: Escherichia coli; Staphylococcus aureus, Pseudomonas aeruginosa and Bacillus cereus, which grown on Mueller Hinton agar (MHA) plates and then treated with different concentrations of rosemary extract (F1) and (F2) ranged from 0.15$1.2 \mathrm{mg} / \mathrm{ml}$, the results revealed that the higher inhibition zone obtained by F1 were $35 \mathrm{~mm}$ in $S$. aureus, $24 \mathrm{~mm}$ in B. cereus and lowest inhibition were $16 \mathrm{~mm}$ in $E$. coli and $P$. aeruginosa at concentration $1.2 \mathrm{mg} / \mathrm{ml}$, and the inhibition were depends on extract concentrations. The MIC value of $\mathrm{F} 1$ was $600 \mu \mathrm{g} / \mathrm{ml}$ against $S$. aureus, 1200 $\mu \mathrm{g} / \mathrm{ml}$ against $B$. cereus and $2400 \mu \mathrm{g} / \mathrm{ml}$ against $E$. coli and $P$. aeruginosa, while the $\mathrm{MIC}_{S}$ values of $\mathrm{F} 2$ were $2400 \mu \mathrm{g} / \mathrm{ml}$ against $S$. aureus and $P$. aeruginosa, and 4800 $\mu \mathrm{g} / \mathrm{ml}$ against $\boldsymbol{E}$. coli and $B$. cereus. Furthermore calculating index fractional inhibitory concentration ( $\sum$ FIC) of rosemary extracts (F1 or/and F2), the $\sum$ FIC $A$ ranged from synergistic to additional on $E$. coli and $P$. aeruginosa respectively, antagonistic on $S$. aueras and $B$. cereus, while the $\sum \mathrm{FIC}_{B}$ index showed synergistic effects on all tested organisms except the additional effect on $P$. aeurginosa on the basis of resultant zone of inhibition. The anticancer effects of (F1) were used on three cell lines, human larynx epidermoid carcinoma (Hep-2), mammary adenocarcinoma (AMN-3), rhabdomyosarcoma (RD) and one normal cell line, Rat embryo fibroblast (REF) at different concentrations ranged from $62.5-1000 \mu \mathrm{g} / \mathrm{ml}$. The highest inhibition rate (IR) was $82.41 \%$, $85 \%$ on RD, 52.62\%, $75.48 \%$ on Hep2, $39.14 \%$ and $49.75 \%$ on $\mathrm{AMN}-3$ at concentrations 500 and $1000 \mu \mathrm{g} / \mathrm{ml}$ after $72 \mathrm{~h}$ exposure time respectively, while IR of Ref cell line exhibit low inhibition rate ranging from 5.8 to $15.7 \%$ after $72 \mathrm{~h}$ in the same conditions.

Key words: antimicrobial, anticancer, Rosmarinus oficinalis , extract, pathogenic 
المستخلص

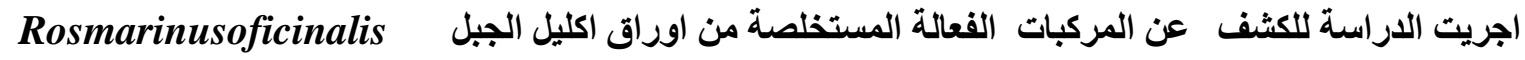

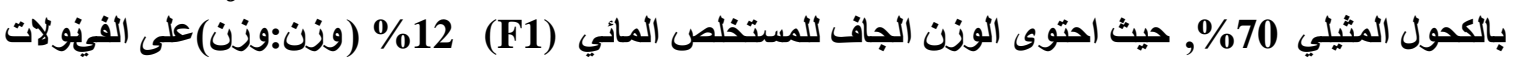

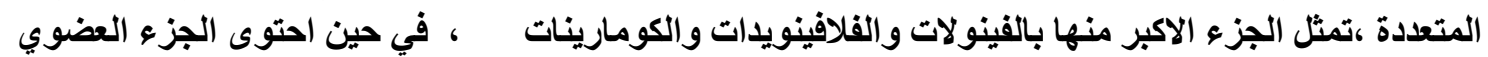

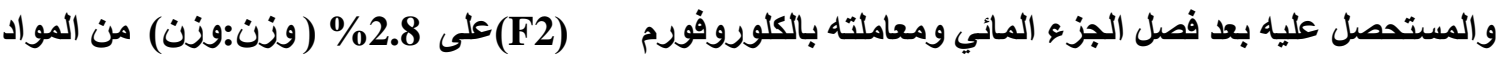

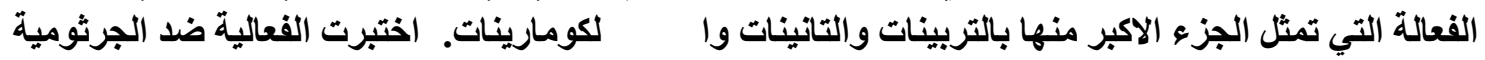

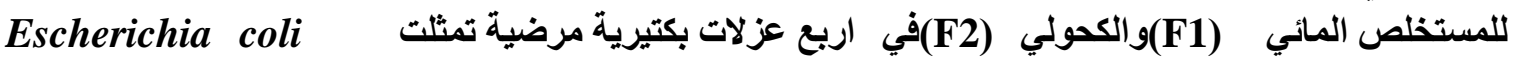
(Bacillus cereus pseudomonas, aeruginosa Staphylococcus aureus،

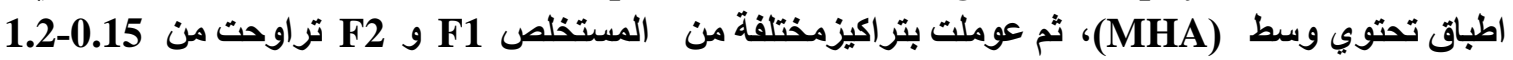

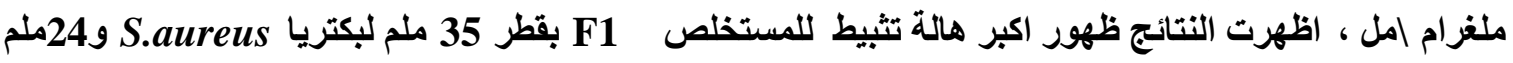

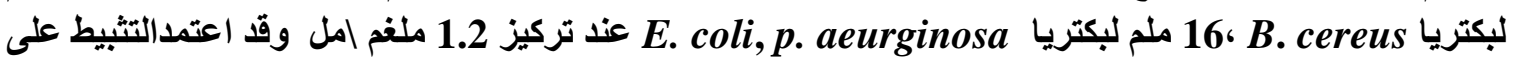

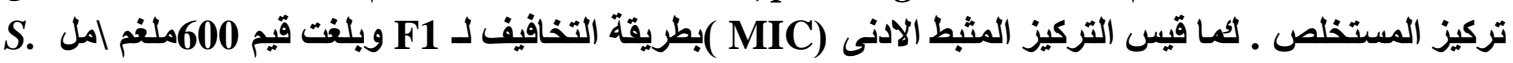

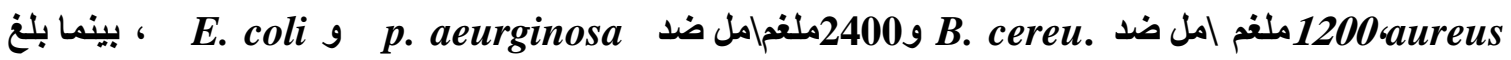

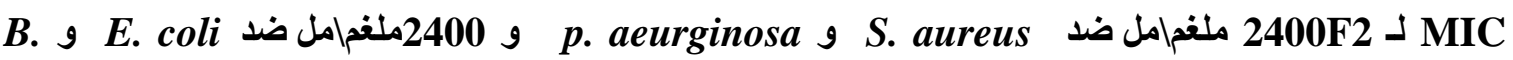

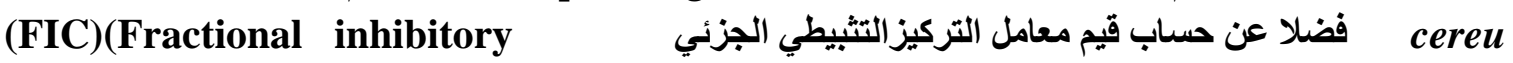

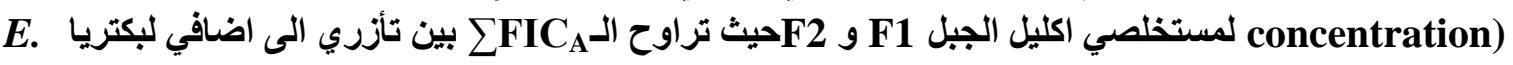

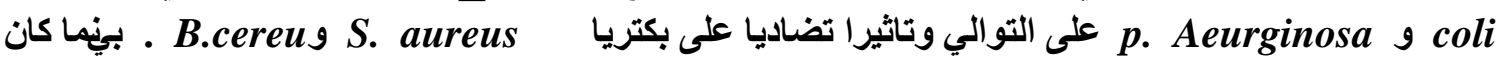

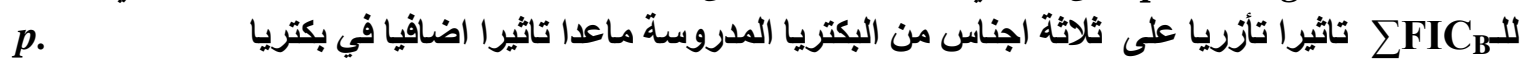
aeurginosa

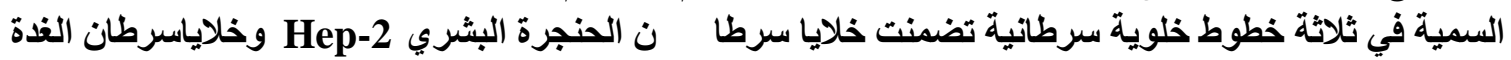

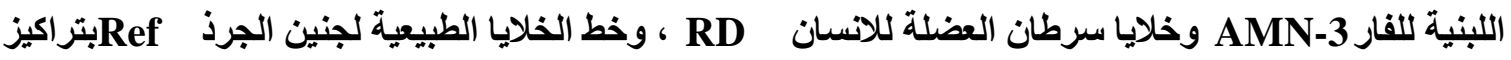

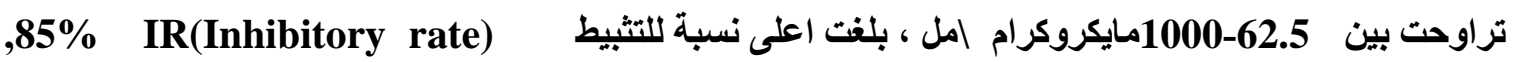

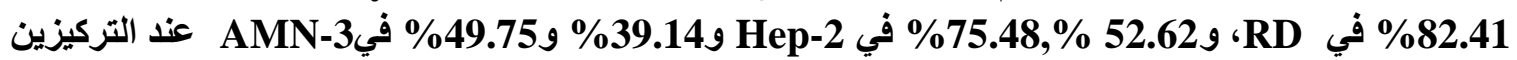

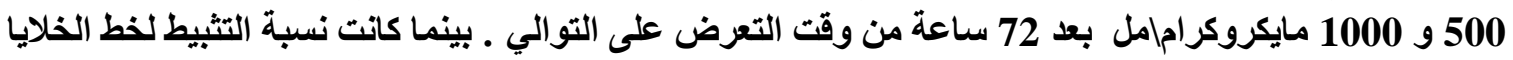

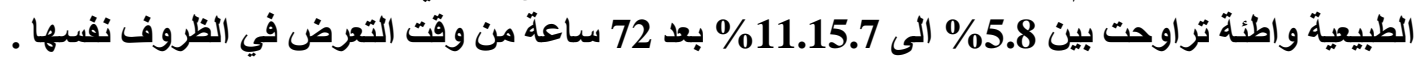

\section{Introduction:}

Rosemary (Rosmarinus officinalis Linn.) is a common household plant grown in many parts of the world. Rosemary is commonly used as a spice, a flavoring agent in food processing and a beverage drink as well as in cosmetics. The distribution of six compounds with three different polyphenol skeletons have been studied in rosemary: phenolic diterpenes (carnosic acid, carnosol, and 12-O-methylcarnosic acid), caffeoyl derivatives (rosmarinic acid), and flavones (isoscutellarein 7-O-glucoside and genkwanin), each showing a characteristic behavior and distribution during the vegetative cycle. Only in leaves were all six compounds present. Rosmarinic acid showed the highest concentrations of all the polyphenols in all organs [1].

The most important constituents are carnosol, carnosic acid, caffeic acid and its derivatives such as rosmarinic acid [2]. These compounds have powerful antioxidant activity that Carnosic acid, the polyphenolic diterpene derived from rosemary, is a strong dietary antioxidant that exhibits antimutagenic properties in bacteria and anticarcinogenic activity in various cell and animal models. The inhibition capacities; of carnosol, rosmanol, and epirosmanol, which are phenolic diterpenes from rosemary, to oxidized low-density lipoprotein (LDL) formation in human blood and detect their scavenging activities to lipid free radical and superoxide anion in vitro [3]. 
Rosemary and its constituents have a therapeutic potential in bronchial asthma, peptic ulcer, prostate disorders, inflammatory diseases, liver toxicity, atherosclerosis, stroke, ischemic heart disease, cataract, leukemia, cancer and poor sperm motility. In folk medicine it is used as an antispasmodic in renal colic and dysmenorrhea, and in relieve respiratory disorders, as well as its extract relaxes smooth muscles of trachea and intestine, and has choleretic, hepatoprotective and antitumerogenic activity [4]. Furthermore, there have been few reports on the volatile components of rosemary. These data suggest that the volatile constituents of a rosemary extract had antioxidative properties [5].

Our study aimed to extract the active constitutions of rosemary and evaluate their antimicrobial activity against some pathogenic bacteria isolates and its synergistic affects with standard antimicrobial compounds, furthermore the cytotoxicity of the rosemary extract on some cancer cell lines.

\section{Materials and methods:}

Plant collection: The dried leaves of rosemary were purchased from traditional and folk medicine store in Baghdad then grained to obtain the powder and store at dry place.

\section{1-extraction of active compounds:}

Active constitutions were extracted according to [6] by mixing 100g of rosemary leaves powder with $400 \mathrm{ml}$ of $70 \%$ methanol by magnetic stirrer for $18 \mathrm{~h}$ at room temperature, then the mixture was filtered through Whatman filter paper No.1 by vacuum pump, the filtrate was kept in clean flask, while the precipitate was remixed with $70 \%$ methanol $(1: 2 \mathrm{w} / \mathrm{v})$ at the same conditions, the obtained filtrate accumulated with the first filtrate. Second step involved evaporation of alcohol from the extract (filtrate), and partially purified with chloroform at ratio 1:5 (v/v) with reparatory funnel. Two layers were formed, upper layer (aqueous phase) (F1) represent polyphenols and the lower layer (organic phase) (F2) represent terpenoids, were collected separately, and dried by lyophilizer. The qualitative chemical tests of the active compounds in extract solutions (F2\&F2) such as phenols were detected according to [7]. Alkaloids, flavonoids and glycosids were detected according to $[8,9]$. Tannins and terpins according to $[10,11]$.

High performance liquid chromatography (HPLC) was accomplished in reveres phase by injection $10 \mu \mathrm{l}$ of rosemarinc acid at a concentration $10 \mu \mathrm{g} \backslash \mathrm{ml}$ (as slandered solutions), and $10 \mu \mathrm{l}$ of fifth times diluted solution (F1) before lyophilization using ODS-C18 column, the mobile phase was $1 \%$ of phosphate buffer: methanol (40: 60) at flow rate $0.5 \mathrm{ml} \backslash \mathrm{min}$ by detector Ach at $254 \mathrm{~nm}$.

\section{2-tested microorganisms:}

The cultures of bacteria were obtained from department of biotechnology, College of Science, University of Baghdad. Two isolates of gram positive bacteria are. S. aureus, $B$ .cereus and two isolates of gram negative bacteria $P$. aeruginosa, E. coli were used to evaluate the antimicrobial activity of aqueous (F1) and alcoholic (F2) extracts. The cultures of bacteria were maintained in their appropriate agar slants at $4{ }^{\circ}$ throughout the study and used as stock cultures. 


\section{3-Antimicrobial assay:}

Screening of rosemary extracts for antimicrobial activity was done by the disk diffusion method [12], which is normally used as preliminary check . It was performed using an $18 \mathrm{hr}$ culture at $37 \mathrm{c}^{\circ}$ in $10 \mathrm{ml}$ of Mueller Hinton broth (MHB ) the culture was adjusted approximately $10^{5}$ cell forming unit/ml(CFU) with sterile saline solution. Five hundred microliters of suspension were spread over the plates containing Mueller Hinton agar (MHA) using a sterile spreader in order to get a uniform microbial growth on both control and test plates.

The rosemary extracts powder (polyphenols and terpenoids) each one was dissolved in $10 \%$ aqueous dimethylsulfoxide (DMSO) then the solubility was complete with phosphate buffer saline (PBS) to prepare stoke solutions, later sterilized by filtration through $0.45 \mu \mathrm{m}$ membrane filter. Under aseptic conditions, empty sterilized disks (Whatman No.5, 6mm diameter) were impregnated with $50 \mu 1$ of different concentrations $(0.15,0.3,0.6,1.2) \mathrm{gm} / \mathrm{ml}$ of respective extract and placed on inoculated culture plate separately, and the plates were left for $30 \mathrm{~min}$ at room temperature to allow the diffusion of extracts ,as well as standard disk containing Streptomycin $(25 \mu \mathrm{g} / \mathrm{disc})$, Ampicillin $(10 \mu \mathrm{g} / \mathrm{disc})$ and Tetracycline $(30 \mu \mathrm{g} / \mathrm{disc})$ were used as reference control, and then the plates were incubated at $37 \stackrel{\circ}{\mathrm{c}}$ for $48 \mathrm{~h}$ under aerobic conditions [13] .

\section{4-Minimum inhibitory concentrations (MIC):}

Four genera of bacterial isolates were re-activated in 10ml MHB. The agar dilution method recommended by clinical laboratory slandered (CLSI) [14] was used with some modifications. A series of two fold dilutions of each extract ranging from $4.8 \mathrm{mg} / \mathrm{ml}$ were prepared in MHA at $48^{\circ}$. plates were dried at room temperature for $30 \mathrm{~min}$ prior to spot inoculation with $10 \mu \mathrm{l}$ aliquots of culture containing approximately $10^{5}$ $\mathrm{cfu} / \mathrm{ml}$ of each organism . Inoculated plates were incubated at $37^{\circ} \mathrm{c}$ for $18 \mathrm{~h}$, and the MIC determined. Experiments were carried out in triplicate.

Incubation of bacterial growth in plates containing tested extracts was judged by comparison with growth in blank control plates. The MICs were determined as the lowest concentration of extract inhibiting visible growth of each organism on the agar plate [15].

\section{5- Combinations test ( $\mathrm{E}$ test):}

An inoculum equal to $0.5 \mathrm{McFarland}$ turbidity standards was prepared from each organism, and $10 \mu \mathrm{l}$ of suspension was inoculated onto MHA plate. E test strip of ampicillin, tetracycline and streptomycin (Sigma chemical co.) were stored at -20 until used. The E test strips were applied to the inoculated culture plates separately by using template as recommended by manufacturer and the plates were incubated at $35 \stackrel{\circ}{\circ}$ for $48 \mathrm{~h}$ under aerobic conditions.

For testing, the combinations of E test of standard antimicrobial and extracts (F1 or F2) solutions, strips were placed on the same culture medium in across formation, with a 90 angle at the intersection between the scales at the respective MICs for organisms, and the plates were incubated at $35 \stackrel{\circ}{\mathrm{c}}$ for $48 \mathrm{~h}$.

Determining MICs by E test were performed in duplicates, according to the recommendations of manufacturers, and the MICs were interpreted at the point of intersection between the inhibition zone and E test strip [16]. 
The fractional inhibitory concentration index $\left(\sum F I C\right)$ was calculated on the basis of the resultant zone of inhibition as follows: $\sum \mathrm{FIC}=\mathrm{FIC}_{\mathrm{A}}+\mathrm{FIC}_{\mathrm{B}}$, where $\mathrm{FIC}_{\mathrm{A}}$ is the $\mathrm{MIC}$ of combination or mixed extract $(\mathrm{F} 1+\mathrm{F} 2) / \mathrm{MIC}$ of drug $\mathrm{A}$ alone (or one extract, $\mathrm{F} 1$ ), and $\mathrm{FIC}_{\mathrm{B}}$ is the MIC of combination or mixed extract $(\mathrm{F} 1+\mathrm{F} 2) / \mathrm{MIC}$ of drug $\mathrm{B}$ alone (or one extractF2) [16].

\section{6- Cell line growth and cytotoxicity assay:}

Human larynx epidermoid carcinoma (Hep-2), mammary adenocarcinoma (AMN-3), Rhabdomyosarcoma (RD) and Rat embryo fibroblast (REF) were obtained from Iraqi center of cancer and medical genetic research, Al Mustansiria University. The cells were grown in RPMI-1640 medium containing 10\% fetal calf serum to form confluent monolayer.

The attached cells washed firstly with PBS and harvested from the flask by treatment with trypsin-versine solution. The cells were counted by trypan-blue (about 95\% viability), then cell suspension used for determination of cytotoxicity, 200 $\mu 1$ of cell suspension were seeded in 96-well microtiter plate at density $1 \times 10^{5}$ cells $/ \mathrm{ml}$ and incubated in $\mathrm{CO}_{2}$ incubator for $24 \mathrm{~h}$ at $37 \mathrm{c}^{\circ}$, then $200 \mu \mathrm{l}$ of different concentration of rosemary extract $(\mathrm{F} 1)(1000,500,250,125,62.5) \mu \mathrm{g} / \mathrm{ml}$ were prepared in serum free media (SFM) and added to cells, then re-incubated the plates for additional $48 \mathrm{~h}$ and $72 \mathrm{~h}$ [17].

Five replicate wells were used for each concentration and negative control wells were treated with SFM . At the end of exposure periods , the cells were stained by $100 \mu 1$ of crystal violet solution and incubated at $37 \stackrel{\circ}{\text { for }} 30 \mathrm{~min}$ [18]. The optical density of each well was read by micro-ELISA reader at $492 \mathrm{~nm}$. The percentage of inhibition was calculated according to [19].

Inhibition rate $($ IR) $=$ (optical density of control wells-optical density of test wells)/optical density of control wells $\times \mathbf{1 0 0}$

Statistical analysis: the experiments data were analyzed using statistical software SPSS version 16, significant differences between control and sample means were assessed using student's T-test and $\mathrm{P}$ values $\leq 0.05$ were considered significant.

\section{Results and discussion:}

\section{Qualitative and quantitative tests of some active compounds in rosemary leave} extract:

Results obtained by qualitative chemical detection indicated the presence of phenols, flavonoids, coumarins, alkaloids and weak indication for tannins and the absence of terpenes, glycoside and saponines in aqueous extract (F1) and the yield of partially purified extract was $12 \%(\mathrm{w} / \mathrm{w})$, while the qualitative tests for organic extract (F2) showed the presence of terpenes, tannins and coumarins as a major compounds and flavonoids, alkaloids and saponine in lowest contents, and the yield of this fraction was $2.8 \%$.

HPLC analysis was accomplished to determine the most important compound in rosemary leave extract (F1) using a rosmarinic acid standard as reference. The result showed in Figure (1) indicates the retention time of standard rosmarinic acid was 6.258 min, while it was $6.624 \mathrm{~min}$ for partially purified polyphenols (rosmarinic acid) in 
aqueous extract F1. So the concentration of rosmarinic acid content was $59 \%$ of aqueous extract according to total peak area (TPA).

(A)

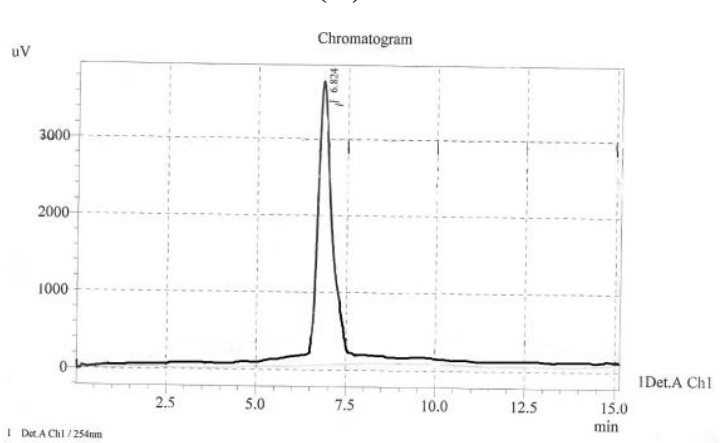

(B)

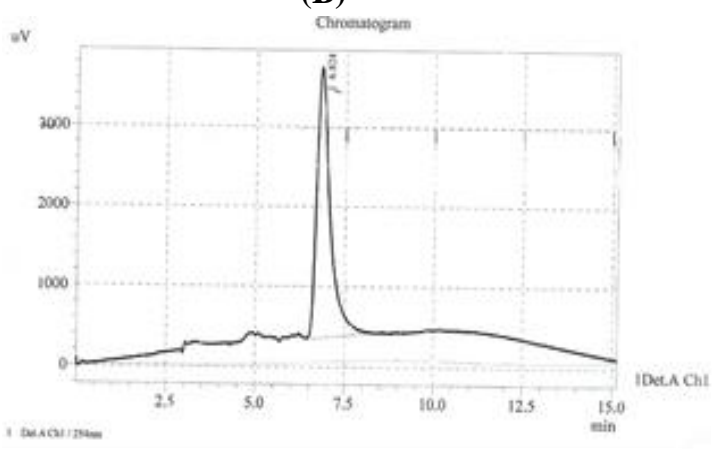

Fig.(1): chromatographic resolution by HPLC for standard rosmarinic acid (A), and fraction components of rosemary leave extracts (F1) (B) in reverse phase of column ODS-C18, mobile phase methanol: phosphate buffer (60:40) at flow rate $0.5 \mathrm{ml} / \mathrm{min}$ reading by detector Ach 1 in $254 \mathrm{~nm}$.

The distribution of compound in aqueous extract (F1)showed the major peak is rosemarinic acid and there are many minor peaks of other compounds that may be carnosic acid, carnosol and other phenolic compounds such as flavonoids, coumarins and phenols. Many researchers revealed many compoundes were detected in rosemary such as [1] recorded the distribution of six compounds with three different polyphenol skeletons have been studied in Rosemrinus officinalis: phenolic diterpenes (carnosic acid, carnosol, and 12-O-methylcarnosic acid), caffeoyl derivatives (rosmarinic acid), and flavones showing a characteristic behavior and distribution during the vegetative cycle. Only in leaves were all six compounds present, and all the highest accumulation rate was related with the young stages of development. Furthermore the 12 different rosemary accessions were obtained dependent on variety polarity of solvent used in extraction [13]. As well as Rosmarinic acid, carnosic acid, and seven of their terpen type metabolites, and seven flavonoids were identified from liquid chromatography-mass spectrophotometric analysis of rosemary, and during the distillation treatment used with plant material, strongly affected the content of the two compounds of higher antioxidant activity, rosmarinic acid and carnosic acid [20].

Our results came in agreements with that obtained by [21], water extract of rosemary containing only $12 \%$ of rosamaric acid, while the methanol extract containing $30 \%$ of carnosic acid, $16 \%$ carnosol and 5\% rosemaric acid. In additional to, our extract were obtained by $70 \%$ methanol might accumulate that compounds.

\section{Antimicrobial activity:}

The antimicrobial activity of rosemary extracts is summarized in Table (1); the results revealed that rosemary extract (F1) showed antibacterial activity with varying magnitudes. The zone of inhibition of resistance depends on that zone diameter limited to control strains of (E. coli ATCC25922, P. aeruginosa ATCC27853 and S. aureus ATCC25923) for NCCLS [22]. Generally most of the tested organisms were sensitive to the polyphenols (F1); the results exhibited a graduated increasing on inhibition depending on increasing the concentration of extracts from 0.15 to $1.2 \mathrm{mg} / \mathrm{ml}$. Significant inhibitory 
effects of F1 were shown against S. auerus $(35 \mathrm{~mm})$, B. cereus $(24 \mathrm{~mm})$, and insignificant effects revealed against $E$. coli and $P$. aeruginosa $(16 \mathrm{~mm})$ depending on extract concentrations. Less differences and insignificant in resistance were found between different concentrations of rosemary terpenes (F2) on tested organisms, and the results showed no inhibition of growth with the negative control (10\% DMSO). The effects of three standard antibiotic disc (Amp, Tetr, Strep) were high susceptibility against local isolates including E. coli, $S$. aureus and P. aeruginosa while B. cereus exhibit resistance on Amp and Tetr, and intermediate susceptibility on Strep, our results compared according to [12].

Table (1): Antimicrobial activity of rosemary leave extracts against growth of tested organisms using disc diffusion method

\begin{tabular}{|c|c|c|c|c|c|c|c|c|c|c|c|}
\hline \multirow{3}{*}{$\begin{array}{l}\text { organisms } \\
\text { Conc. }(\mathrm{mg} / \mathrm{ml})\end{array}$} & \multicolumn{8}{|c|}{ Diameter of zone of inhibition (mm)caused by } & \multirow{2}{*}{\multicolumn{3}{|c|}{$\begin{array}{c}\text { Inhibition zone }(\mathbf{m m}) \text { for } \\
\text { standard antibiotic } \\
\text { disk }\end{array}$}} \\
\hline & \multicolumn{4}{|c|}{$\begin{array}{c}\text { F1 }(\mathbf{m g} / \mathrm{ml}) \\
\text { Aqueous extract }\end{array}$} & \multicolumn{4}{|c|}{$\begin{array}{c}\mathrm{F} 2(\mathrm{mg} / \mathrm{ml}) \\
\text { Organic extract }\end{array}$} & & & \\
\hline & 0.15 & 0.3 & 0.6 & 1.2 & 0.15 & 0.3 & 0.6 & 1.2 & Amp & tetr & strept \\
\hline E. coli & 13 & 10 & 15 & 16 & 12 & 12 & 12 & 12 & 35 & 25 & 28 \\
\hline S.aureus & 15 & 30 & 32 & 35 & 8 & 12 & 14 & 16 & 32 & 43 & 30 \\
\hline B. cereus & 12 & 17 & 22 & 24 & 10 & 10 & 10 & 12 & 10 & 11 & 15 \\
\hline P. aeruginosa & 14 & 16 & 15 & 16 & 14 & 14 & 15 & 17 & 35 & 28 & 22 \\
\hline
\end{tabular}
compounds. Carnosic acid and rosemarinic acid may be the main bioactive antimicrobial compounds present in rosemary extract. Rosemary extract may be a good candidate for functional food as well as pharmaceutical plant-based product [21]. The inhibition zones obtained by our experiments were comparable with standard inhibition zones recorded for antibiotics to standard strains [8]. The antioxidant activity of tow extracts referred to its different polyphenolic compositions that were evaluated in methanolic system that clearly suggest as expellant antioxidant [1]. To achieve effective treatment, antimicrobial that can be penetrating cell at high concentration should be determined, and the duration of therapy should be set properly [22].

\section{Minimum inhibitory concentration (MIC):}

Minimum inhibitory concentration (MIC) for testing extracts ranged from 150 to 4800 $\mu \mathrm{g} / \mathrm{ml}$ showed in Table (2). This experiment revealed that rosemary polyphenols (F1) recorded maximum activity with MIC values ranging from 600 to $4800 \mu \mathrm{g} / \mathrm{ml}$ against $S$. aureus and $1200-4800 \mu \mathrm{g} / \mathrm{ml}$ against $B$. cereus followed by MIC values ranging from $2400-4800 \mu \mathrm{g} / \mathrm{ml}$ against $E$. coli and $P$. aeruginosa, whereas all concentrations of rosemary terpenes (F2) showed moderate MIC values concentration $(2400 \mu \mathrm{g} / \mathrm{ml})$ against $S$. aureus and $P$. aeruginosa and slight MIC values against E. coli and B. cereus. While the mixed rosemary extract (F1and F2) not always revealed maximum activity with the MIC values against tested bacteria, a variety differences results in susceptibility was found as shown in Table (2). 
Table(2): Minimum inhibitory concentrations (MIC) of rosemary (aqueous F1 and organic extracts F2) extracts separately and combined and standard antimicrobial solutions on tested bacteria.

\begin{tabular}{|c|c|c|c|c|c|c|c|c|}
\hline \multirow{2}{*}{ organism } & \multicolumn{3}{|c|}{ MIC conc. $(\mu \mathrm{g} / \mathrm{ml})$} & \multicolumn{2}{|c|}{ FIC index according to } & \multicolumn{3}{|c|}{ MIC conc. $(\mu \mathrm{g} / \mathrm{ml})$ of } \\
\hline & F1 & $\mathbf{F} 2$ & $\mathbf{F} 1+\mathbf{F} 2$ & $\begin{array}{l}\operatorname{Mix}(\mathbf{F 1 \& F 2}) / \mathbf{F 1} \\
\sum \mathrm{FIC}_{\mathrm{A}}\end{array}$ & $\begin{array}{l}\operatorname{Mix}(\mathbf{F} 1 \& \mathbf{F} 2) / \mathbf{F 2} \\
\sum \mathrm{FIC}_{\mathbf{B}}\end{array}$ & $\begin{array}{l}\text { Antim } \\
\text { solutic } \\
\text { Amp. }\end{array}$ & $\begin{array}{l}\text { crobia } \\
\text { ns tetr } \\
\text { trep. }\end{array}$ & \\
\hline E. coli & 2400 & 4800 & 600 & 0.255 & 0.125 & 256 & 1024 & 512 \\
\hline S. aureus & 600 & 2400 & 1200 & 2 & 0.5 & 512 & 128 & 512 \\
\hline B. cereus & 1200 & 4800 & 2400 & 2 & 0.5 & 1024 & 2048 & 1024 \\
\hline P.aeruginosa & 2400 & 2400 & 2400 & 1 & 1 & 256 & 512 & 1024 \\
\hline
\end{tabular}

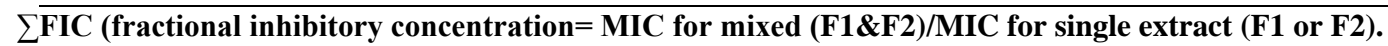
$\leq 0.5$ syn, $0.5-\leq 1$ additional, $1-\leq 2$ uneffected, $>2$ antagonistic [23].

According to $\mathrm{FIC}_{\mathrm{A}}$ and $\mathrm{FIC}_{\mathrm{B}}$ index, many concentrations of $\mathrm{F} 1$ or $\mathrm{F} 2$ were tested separately on microorganisms, $\sum \mathrm{FIC}_{\mathrm{A}}$ ranged from synergistic to additional on $E$. coli and $P$. aaruginosa respectively, antagonistic on $S$. aueras and B. cereus while the $\sum \mathrm{FIC}_{\mathrm{B}}$ index showed synergistic effects on three tested microorganisms and the additional effect on $P$. aeruginosa Table (2) [23].

The MIC values of Amp against $E$. coli and $P$. aeruginosa were $\geq 256 \mu \mathrm{g} / \mathrm{ml}$, while it was $\geq 512 \mu \mathrm{g} / \mathrm{ml}$ on $S$. aureus and was $1024 \mu \mathrm{g} / \mathrm{ml}$ against B. cereus. The lowest MIC values of tetra were recorded from $128-2048 \mu \mathrm{g} / \mathrm{ml}$ on $S$. aureus, and from $512-2048 \mu \mathrm{g} / \mathrm{ml}, 1.02-$ $2048 \mu \mathrm{g} / \mathrm{ml}$, and $\geq 2048 \mu \mathrm{g} / \mathrm{ml}$ against $P$. aeruginosa, E. coli and B. cereus respectively, while MICs values of streptomycin ranging from $512-2048 \mu \mathrm{g} / \mathrm{ml}$ against $E$. coli, and $S$. auereus, and from 1024-2048 $\mu \mathrm{g} / \mathrm{ml}$ against $B$. cereus and $P$. aeruginosa Table (2).

The MIC of ethanolic extract of rosemary was $1 \%(100 \mathrm{mg} / \mathrm{ml})$ for gram positive bacteria including Lecuconostoc mesnteroides, $0.5 \%$ for Listeria monocytogenes and Staphylococcus, $0.13 \%$ for Streptococcus mutanus, $0.06 \%$ for Bacillus cereus, while up to $1 \%$ of ethanolic solution had no activity on gram negative bacteria such as E. coli, salmonella and Erwinia [24].

Methanol extract of rosemary containing 30\% carnosic acid, 16\% crnosol and 5\% rosemarinic acid were the most effective antimicrobial compounds tested against G+ve bacteria, MIC between 2-15 $\mu \mathrm{g} / \mathrm{ml}$, MIC for G-ve bacteria 2-60 $\mu \mathrm{g} / \mathrm{ml}$, by contrast, water extract containing only $15 \%$ rosemarinic acid showed narrow activity [14], as well as the MIC values of rosemary oil were recorded on gram positive and gram negative bacteria ranged from 6.4- $12.8 \mathrm{mg} / \mathrm{ml}$ [23].

By E test, the $\sum \mathrm{FIC}_{\mathrm{A}}$ results of the combination of respective MICs of rosemary extracts and the antimicrobial solutions, F1-amp. Yield synergy against E .coli and P. aeruginosa and yield additional against st.aureus and B. epidermis, whereas $\sum$ FIC results of the combination of F1-tetra and F1-strep yield synergistic against $S$. aureus, additional against $E$. coli and $P$. aeruginosa, while there were antagonistic $\geq 2$ against $B$. cereus Table (3). From other point the $\sum \mathrm{FIC}_{\mathrm{B}}$ index of the combination of F2-Amp, F2-tetra and F2-strep. Yield unaffected and antagonistic against all tested organisms Table (3). 
Table (3): Fractional inhibitory concentration (FIC) index of standard antimicrobial solutions and rosemary extracts against tested organisms obtained by E-test.

\begin{tabular}{lllllll}
\hline \multicolumn{1}{c}{$\begin{array}{c}\text { Tested } \\
\text { organisms }\end{array}$} & & \multicolumn{2}{c}{$\sum$ FIC $_{\mathrm{A}}$ activity } & $\sum$ FIC $_{\mathrm{B}}$ activity & \\
& F1-Amp & F1-tetra & F1-strep & F2-Amp & F2-tetra & F2-strep \\
E. coli & 0.5 & 1 & 1 & 1 & 2 & 1 \\
S. aureus & 1 & 0.5 & 0.5 & 1 & 1 & 1 \\
B. cereus & 1 & 2 & 3 & $<1$ & $>2$ & 2 \\
P.aeruginosa & 0.5 & 1 & 1 & 1 & 1 & 2 \\
\hline
\end{tabular}

Even through of these experiments, different conditions and end points have been used. There was frequent agreement between the results of the two methods (E-test and checkerboard) [13]. A comparable results were obtained throughout our experiments using E-test and disc diffusion, also Manoharan, et al 2003 [24] revealed over all agreement results of E-test and agar dilution method for some standard antimicrobial solutions (100\% cefotaxime and ampicillin and least for chloramphenicol 92\%). Incorporation of carnosic acid and carnosol into the growth media at $10 \mu \mathrm{g} / \mathrm{ml}$ caused a 32 and 16 fold potentially of the activity of erythromycin against erythromycin-effluxing strains, respectively [25].

Further comparison of E-test technique with MICs methods for determination of synergy is warranted. E test can easily applied to antibiotic susceptibly test as it is less labor, intensive and less time consuming. The standardization of these techniques for routine laboratory testing is needed because of the common therapies against growing numbers of multi-drag resistant strain [26].

\section{Effects of rosemary extract on growth of tumor and normal cell lines:}

The in vitro growth inhibitory effects of rosemary extract (F1) was assayed for five concentrations $(1000,500,250,125,62.5) \mu \mathrm{g} / \mathrm{ml}$ against three tumor cell lines (Hep-2, AMN-3 and RD), and one normal cell line (REF). The results showed in figure (2-A) revealed a significant $(\mathrm{P}<0.05)$ increasing inhibition rate of Hep-2 cultured cells as compared to control cultures, ranging from $5.6 \%$ to $50.81 \%$ and $12.19 \%$ to $75.48 \%$ at concentrations ranged from 62.5 to $1000 \mu \mathrm{g} / \mathrm{ml}$ at $48 \mathrm{~h}$ and $72 \mathrm{~h}$ of exposure time respectively.

The growth inhibition rate of AMN-3 cultured cells revealed moderate effects in significant increasing caused by increasing concentrations of rosemary extract from 62.5 to $1000 \mu \mathrm{g} / \mathrm{ml}$, inhibition rate ranging from $9.62 \%$ to $36.64 \%$ and from $23.27 \%$ to $49.75 \%$ at exposure time $48 \mathrm{~h}$ and $72 \mathrm{~h}$ respectively figure (2-B).

The pattern of inhibition was highest significant $(\mathrm{P} \leq 0.05)$ in $\mathrm{RD}$ cultured cells as compared with control cultures, the rate ranging from $43.35 \%$ to $89.41 \%$ and from $70.07 \%$ to $85.03 \%$ at $48 \mathrm{~h}$ and $27 \mathrm{~h}$ of incubation in concentrations from 62.5 to $1000 \mu \mathrm{g} / \mathrm{ml}$ respectively figure $(2-\mathrm{C})$. The inhibition rate was concentration dependent, as well as time dependent on three tested tumor cell lines, except the inhibition rate on RD cells at concentrations $62.5,125$ and $250 \mu \mathrm{g} / \mathrm{ml}$ after $72 \mathrm{~h}$ which showed insignificant differences depending on these concentrations.

The inhibition rate was also concentration and time dependent on normal cell (REF); since mild effects of inhibition less than $10 \%$ were revealed at concentrations, 500 and $1000 \mu \mathrm{g} / \mathrm{ml}$ after $48 \mathrm{~h}$ and at concentrations $(62.5,125,250) \mu \mathrm{g} / \mathrm{ml}$ while slight effects 
were detected at concentrations 500 and $1000 \mu \mathrm{g} / \mathrm{ml}$ after 48 and $72 \mathrm{~h}$ of exposure time figure (2-D).
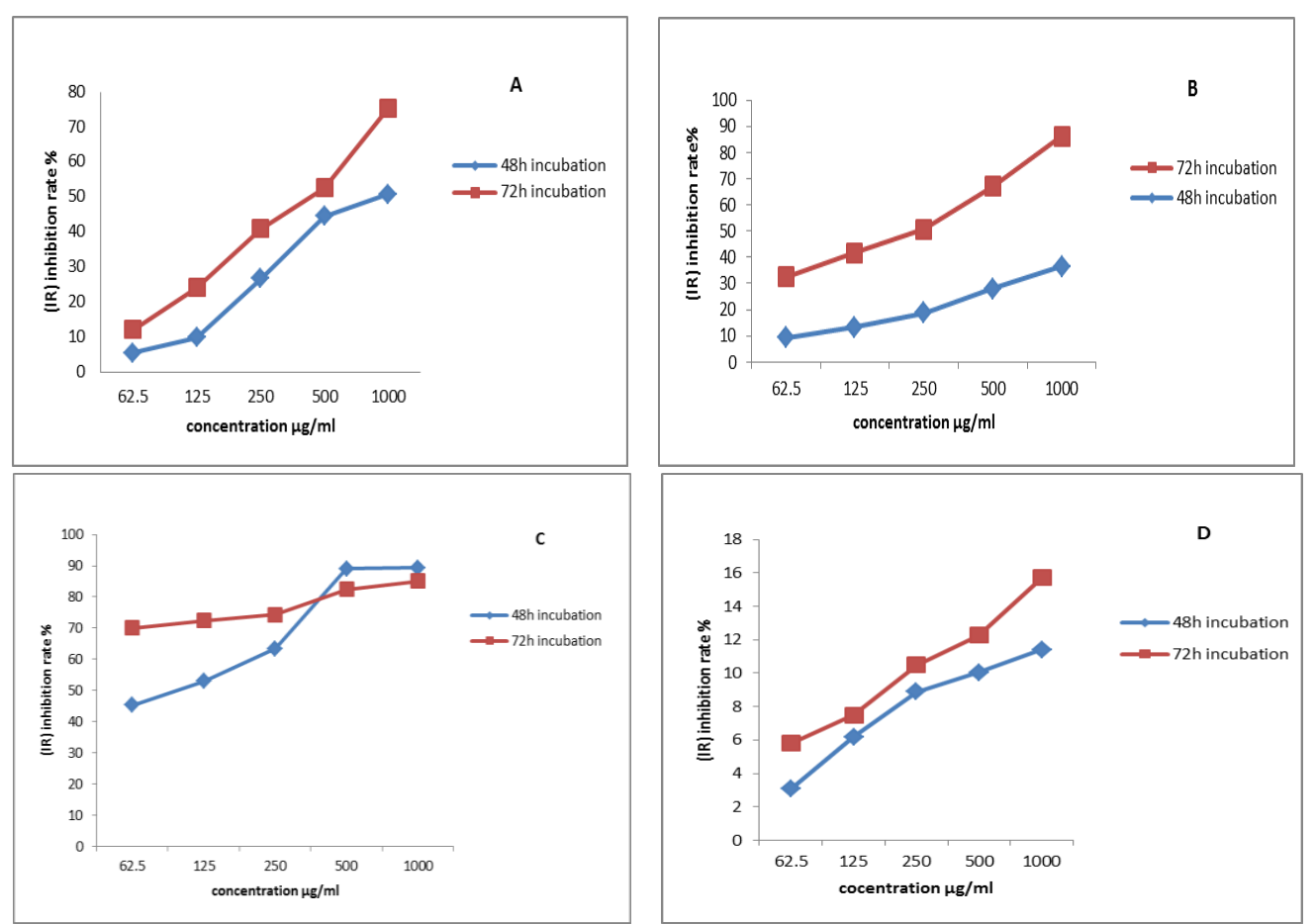

Fig. (2): Effects of rosmarinus offcinalis leaves extract (F1) at different concentrations on percentage of inhibition rate (IR) of tumor cell lines [Hep-2(A), AMN-3 (B), RD (C)] and normal cell line (REF) (D) after 48h and 72h of exposure time.

Cytotoxicity screening models reveals important preliminary data to help in selection plant extracts with potential antineoplastic properties [27]. However the present study showed that rosemary extract (polyphenol, F1) inhibit significantly the proliferation of human tumor cell lines RD $>$ Hep2 $>$ AMN-3 and its activity is concentration and time dependent.

These effects can be referred to the nature and chemical constituents of rosemary extract (polyphenol), mainly rosmarinic acid (’่-o-caffeoyl-3,4dihydroxy phenl lactic acid) which has been observed to possess and anti-cancer properties[28] and antioxidant activities, these effects may be due to (carnosic acid, carnosol, and 12-O-methylcarnosic acid to induce the enzymes such as cyclooxygenase (COX) aids the defense mechanisms in the body to detoxify carcinogens and xenobiotic, as well as reduce oxidative stress[29]. And induce the proapoptotic genes (BAX) and reduce antiapoptotic genes [30].

These results are in agreement with the result of [31] (Ros A) rosmarinic acids inhibit Jurkat cell proliferation by altering the expression of cyclins and cyclin-dependent kinases and induce apoptosis [30] Similar results indicated that rosemary extract have anti-proliferative activities and growth inhibition on various cancer cell lines including colon and breast cancer cell lines and in nonmalignant mammary epithelial cells. Researchers have had promising results in studies of its efficacy against breast cancer, prostate cancer, colon cancer, leukemia and skin cancer [31]. The anticancer effect has been suggested to be mediated through induction of p53 expression which causes cell cycle arrest and apoptosis [32]. Furthermore, the antineoplastic effect of rosemary extract 
(carnosic acid) based on increase intercellular accumulation of common used chemothereputic agents including doxorubicin and vinblastine in cancer cell [33].

\section{References}

1. Del Bano, MJ., Lorente, J., Castillo, J., Benavente-Garcia, O., DelRio, JA., Ortuno A., Quirin, KD. and Gerard, D. (2003). phenolic diterpiebs,flavones and rosemarinic acid distribution during the development of leaves, flowers, stems and roots of Rosemarinus officinalis. Antioxidant activity. J. Agric food Chem. 51(15):4247-53.

2. Ozcan, M. (2003). Antioxidant activities of rosemary, sage and sumac extracts and their combinations on stability of natural peanut oil. J. Med food. 6(3):267-270

3. Steiner, M., Priel, L., Giat, J., Levy, J., Sharoni, Y. and Danilenko, M. (2001). Carnosic acid inhibits proliferation and augments differentiation of human leukemic cells induced by 1,25-dihydroxyvitamin D3 and retinoic acid. Nutr Cancer. 41(1-2):135-144.

4. Al-Sereitiay, MR., Abu-Amerb, KM. and Sena, P. (1999). Pharmacology of rosemary (Rosmarinus officinalis linn.) and its therapeutic potentials. Indian J Exp Biol. 37:124-131.

5. Inoue, K., Takano, H., Shiga, A., Fujita, Y., Makino, H., Yanagisawa, R., Kato, Y. and Yoshikawa, T. (2006). Effects of volatile constituents of rosemary extract on lung inflammation induced by diesel exhaust particles. Basic Clin Pharmacol Toxicol. 99(1): 52-57.

6. Markham, K.R. (1982).Techniques of Flavonoid Identification. Academic Press. Pp: 15-16.

7. Harborne, J. B. (1984). Phytochemical Methods. $2^{\text {nd }}$ ed. Chapman \& Hall, London. P5.

8. Sousek, J., Guedon, D., Adam, T., Bochorakova, H., Taborska, E., Valka, I. and Simanek, V. (1999). Alkaloids and organic acid content of eight Fumaria species. J.Phytochemical analysis. 10:6-11.

9. Al-Shahaat, N. A. Z. (1986). Plants and Medicinal Herbs. Dar Al-Behaar, Beirut. Pp 140-146. Cited in: Sa'eed, O. F. (2004). The effect of Green and Black Tea Extracts on Different Cell Lines in Vitro. M.Sc. Thesis, College of pharmacy, University of Mosul, Iraq.

10. Evans, W. C. (1997). Trease and Evans' pharmacognosy. ( $4^{\text {ed }}$ ed).W. B. Saunders Company. pp. 225-227, Cited in: Sa'eed, O. F. 2004.

11. Shihata, I., M. (1951). A pharmacological study of Anagallis arvensis. M.D. Thesis, Cairo University, Egypt.

12. Vandepitte, J., Engbaek, K., Piot, P. and Heuck, C. C. (1991). Basic laboratory procedures in clinical biotechnology. World Health Organization. Geneva. P85.

13. Del Campo. J., Amiot, M J. and Nguyen, C. (2002). Antimicrobial effect of rosemary extract. J. Food Prod. 63(10):1359-1368.

14. NCCLS (national committee for clinical laboratory standards): methods for dilution antimicrobial susceptibility tests of bacteria through aerobically; In: approved standard M100-S12. (2002). Wayne, PA, NCCLS. 
15. Delaquis, PJ., Stanich, K., Girard, B. and Mazza, G. (2002). Antimicrobial activity of individual and mixed fractions of dill, cllantro, coriander and eucalyptus essential oils, Inter. J Food Microbiol.74:100-109.

16. Orhan, G., Bayram A., Zer Y and Balci, I. (2005). Synergy tests by E test and checker board methods of antimicrobial combination against Brucella melitensis. J. clinical microbiology. 43(1): 140-143.

17. Freshney, R.I. (1994). Culture of animal cells: A manual for basic technique. ( $3^{\text {ed }}$ ed.). Wily-Liss, A John Wiley \& Sons Inc. publication, New York.

18. Mather, J.P. and Roberts, P.E. (1998). Introduction to cell and tissue culture theory and technique. Plenum Press, New York.

19. Chiang, L.C., Chiang, W., Chang, M.Y. and Lin, C.C. (2003).In Vitro Cytotoxic, Antiviral and Immunomodulatory Effects of Plantago major and Plantago asiatica. The American Journal of Chinese Medicine. 31(2): 225-234.

20. Almela, L., Muoz, B., Fernndez, L., Pez, JA., Roca, MJ. and Rabe, V. (2006). Liquid chromatographic-mass spectrometric analysis of phenolics and free radical scavenging activity of rosemary extract from different raw material. J.chromatogr A. 1120(1-2):221-229.

21. Moreno, S., Scheyer, T., Romano, CS. and Vojnov, AA. (2006). Antioxidant and antimicrobial activities of rosemary extracts linked to their polyphenol composition. Free Radic Res. 40(2):223-231.

22. Young, E.J. (2000). Brucella species, Principle and practice of infectious disease. Mandell, G., Bennett, J.I. and Dolin, R. Churchill Livingstone, New York, N. Y. vol. 2.

23. Koneman, E.W., Allen, S. D., Jawa, M.W. and Sachreckeber, P. C. (1992).Color atlas and text book of diagnostic microbiology. J.B. Lippincott, company, Philadelphia. $4^{\text {th }}$ ed,

24. Manoharan, A., Pai, R., Shankar, V., Thomas, K. and Lalitha, M.K.(2002). Comparison of disc diffusion and $\mathrm{E}$ test methods with agar dilution for antimicrobial susceptibility testing at Haemophilus influenzae. Indian J. Med. Res.117:81-77.

25. Oluvatuyi, M., Kaatz, GW. and Gibbons, S. (2004). Antimicrobial and resistance modifying activity of Rosmarinus officinalis. Phytochemistry. 65(24):3249-3254.

26. White, R. L., Burgess, M., Manduru, M. and Bosso, J. A. (1996). Comparison of three different in vitro methods of detection synergy; time kill, checkerboard and $\mathrm{E}$ test. Antimicrob. Agents chemother. 40: 1914-1918.

27. Cardellinall, J.H., Fuller, R.W., Gamble, W.R., Westergard, C., Boswell, J., Munro, M.H.G., Currens, M. and Boyel, M. (1999). Evolving strategies for the selection dereplication and prioritization of antitumor and HIV- inhibitory natural products extracts. In: Bohlin, L. and Bruhn, J.G. (Eds), Bioassay Methods in Natural Products Research and development. Kluwer Academic Publisher, Dordrech. 2536. 
28. Al-Sereiti, MR., Abu-Amer, KM. and Sen, P. (1999). Pharmacology of rosemary (Rosmarinus officinalis Linn.) and its therapeutic potentials. Indian J Exp Biol. 37:124-130.

29. Osakabe, N., Takano, H., Sanbongi, C., Yasuda, A., Yanagisawa, R., Inoue, K. and Yoshikawa, T. (2004). Anti-inflammatory and anti-allergic effect of rosmarinic acid (RA); inhibition of seasonal allergic rhinoconjunctivitis (SAR) and its mechanism. Biofactors. 21:127-131.

30. Kolettas, E., Thomas, C., Leneti, E., Skoufos, I., Mbatsi, C., Sisoula, C., Manos, G. and Evangelou, A. (2006) Rosmarinic acid failed to suppress hydrogen peroxidemediated apoptosis but induced apoptosis of Jurkat cells which was suppressed by Bcl-2. Mol Cell Biochem. 285(1-2):111-120.

31. Ngo, SN., Williams, D. B. and Head, RJ. (2011). Rosemary and cancer prevention: preclinical perspectives. Crit Rev Food Sci Nutr. 51 (10): 946-954.

32. Pei-Wen, Z., Lien-Chai, C. and Chun-Ching, L. (2005). Rosmarin acid induced apoptosis through p33-dependent pathway in human cervical carcinoma cells. Life sci. 76:1367-1379.

33. Plouzek, CA., Ciolino, HP., Clarke, R. and Yeh, GC. (1999). Inhibition of Pglycoprotein activity and reversal of multidrug resistance in vitro by rosemary extract. Eur J. cancer. 35(10):1541-1545. 